\title{
Effect of intracortical vascular endothelial growth factor infusion and blockade during the critical period in the rat visual cortex
}

\author{
Enrike G. Argandoña, ${ }^{a, *}$, Harkaitz Bengoetxea ${ }^{b}$, Susana Bulnes ${ }^{b}$, Irantzu Rico-Barrio ${ }^{b}$, \\ Naiara Ortuzar ${ }^{b}$, Jose V. Lafuente \\ ${ }^{a}$ Department of Medicine. Unit of Anatomy. University of Fribourg, Rue Albert Gockel 1, CH-1700 Fribourg, Switzerland \\ b Laboratory of Experimental Neuroscience LaNCE, Department of Neuroscience, University of the Basque Country (UPV/EHU), Sarriena \\ Auzoa, E-48940 Leioa, Spain
}

\begin{abstract}
VEGF is the major angiogenic and vascular permeability factor in health and disease. Vascular development depends on function, and in sensory areas is experience-dependent. Our aim was to investigate, qualitatively and quantitatively, the effects of intracortical infusion and neutralisation of VEGF during the first days of the critical visual period, when peak levels of endogenous VEGF secretion are reached.

VEGF was intracortically delivered into middle cortical layers of P18 Long-Evans rats. Another cohort received anti-VEGF. Vehicle (PBS)-infused and non-operated animals were used as controls. Various immunopathological analyses were performed: Endothelial Barrier Antigen (EBA) for the BBB integrity and GFAP for astroglial response. Vascular density was measured by Butyryl Cholinesterase Histochemistry, neuronal density by NeuN immunohistochemistry and apoptosis by TUNEL staining. VEGF levels were measured by Western Blot.

Decreased vascular permeability was evoked in VEGF-infused rats whilst EBA expression remained constant, suggesting a preserved BBB function. When VEGF was blocked, tissue showed a higher degree of extravasation and a decreased number of EBA-positive vessels surrounding the injury. Lesion induced by cannula implantation annulled the normal increase in vascular density and the decrease in neuronal density during this time. VEGF rescued in part the vascular increase, and also prevented physiological and pathological neuronal death. VEGF blockade induced a higher amount of neural loss and lower astrocytic reaction.

Our results support the role of VEGF as extending beyond vascularization, preventing physiological and pathological neuronal death, not only in the injured hemisphere but also in the intact one suggesting a process of transhemispheric diaschisis.
\end{abstract}

\footnotetext{
All authors contributed equally in the design of the experiment, the experimental procedures, the analysis of the results and the elaboration of the manuscript.

*Corresponding author. Fax: +41 263009733.

E-mail address: enrique.argandona@unifr.ch (E.G. Argandoña).
} 
1.

\section{Introduction}

Vascular Endothelial Growth Factor (VEGF) is a hypoxiainducible secreted homodimeric glycoprotein of 45,000 Da that plays a major role in developmental (Ferrara and Bunting, 1996; Ferrara and Davis-Smyth, 1997; Ferrara and Gerber, 2001; Ferrara et al., 2003) and pathological angiogenesis (Plate et al., 1992; Dvorak, 2000; Marti et al., 2000; Greenberg and Jin, 2005; Lafuente et al., 2006; Ruiz de Almodovar et al., 2009). In pathological conditions, VEGFR mediates an antiapoptotic effect through Phosphoinositide 3-kinase (PI3K)-dependent signaling pathways that promote the survival of endothelial cells induced by VEGF (Jin et al., 2000, 2001; Geretti et al., 2008) and is related to the blood-brain barrier (BBB) opening in brain injury (Fischer et al., 2002; Lafuente et al., 2006; Ortuzar et al., 2010). A neuroprotective role for VEGF via VEGFR-2 has also been described (Oosthuyse et al., 2001; Storkebaum et al., 2004; Moser and Humpel, 2005; Ortuzar et al., 2011), which occurs via the PI3k/Akt and the mitogen-activated protein kinase/ERK kinase/extracellular signal-regulated protein kinase (MEK/ERK) pathways (Wick et al., 2002; Kaya et al., 2005).

As has been pointed out before, VEGF mediates vascular permeability, inducing a leakage of the BBB in some pathological situations (Fischer et al., 1999; van Bruggen et al., 1999; Schoch et al., 2002; Nordal and Wong, 2005). In addition, VEGF is a potent activator of astroglial response (Krum et al., 2002).

Some authors have studied the post-traumatic effects of VEGF administration and inhibition in adults, where scarce endogenous VEGF secretion remains (Krum et al., 2002; Krum and Khaibullina, 2003). Among the observed effects, the inhibition of VEGF receptor 2 increases lesion area and cellular death (Skold et al., 2006). Outside the brain, the blockade of VEGF by polyclonal antibodies impedes the fracture healing process (Chu et al., 2009). Authors report that VEGF plays an important role as an endogenous cytoprotective mechanism and that VEGF induces both BBB permeability and inflammation on a dose-dependent basis (Dobrogowska et al., 1998; Fischer et al., 2002; Croll et al., 2004).

Less research, however, has been done on the pathophysiology of traumatic brain injury in the developing brain. Despite the general belief that the young brain is more resilient to injury than the adult brain, lesions at an early age often produce more severe effects than equivalent lesions in adults, or evolve in a completely different way (Payne and Lomber, 2002; Tong et al., 2002; Kolb and Cioe, 2003; Anderson et al., 2011). Clinical experience suggests that injury to the immature brain can result in abnormal development and long-standing neurobehavioral impairment (Giza et al., 2005) even if there is little evidence of morphological damage.

Experience modulates the postnatal development of the rat visual cortex in order to shape functional and anatomical cortical architecture. These changes lead to an increase in metabolic demand (Black et al., 1990; Harrison et al., 2002) that is satisfied by the adaptive remodeling of the vascular network (Sirevaag et al., 1988; Argandoña and Lafuente, 1996; Tieman et al., 2004; Bengoetxea et al., 2008).
Most of the cortical changes induced by experience occur during a critical period early in postnatal life (Berardi et al., 2000; Hensch, 2005; Argandoña et al., 2009). This time window is specific for each sensory cortex, and when experiencemediated reorganization of the cortex finishes, sensory functions reach maturity. In rats, for the visual system, this period starts at the end of the third postnatal week, peaks during the fourth week and declines from the end of the sixth week (Duchen, 1992; Fagiolini et al., 1994; Gilbert, 1998).

Previously, we have studied the effects of visual experience on the cortex vasculature, reporting that during the critical period the vascular density and the maturation of the vascular pattern correspond to the level of activity (Argandoña and Lafuente, 1996, 2000, 2002; Argandoña et al., 2005).

The aim of the present study was to investigate the qualitative and quantitative effects of intracortical infusion and neutralisation of VEGF on the visual cortex by the implantation of an osmotic minipump during the first days of the critical visual period in rats, when peak levels of endogenous VEGF secretion are reached.

\section{Results}

\subsection{Lesion produced by cannula placement}

\subsubsection{Neuropathology of the cortical injury}

Minipump cannula produced a cortical injury about $0.8 \mathrm{~mm}$ in depth, rostral to the primary left visual cortex (Fig. 1). Following the injury produced by this small puncture, the rat cortex showed a microlesion, which developed, evolving from microtrauma to micronecrosis. The surrounding tissue showed a variable degree of necrosis and sponginess depending on the infused substance.

In VEGF-infused rats there was a damaged region around the edge of the infusion track defined by numerous necrotic bodies (Fig. 2a). This region seemed to have disappeared in the vehicle and anti-VEGF groups (Fig. 2b). This damaged area surrounding the core of the lesion, presents sponginess and

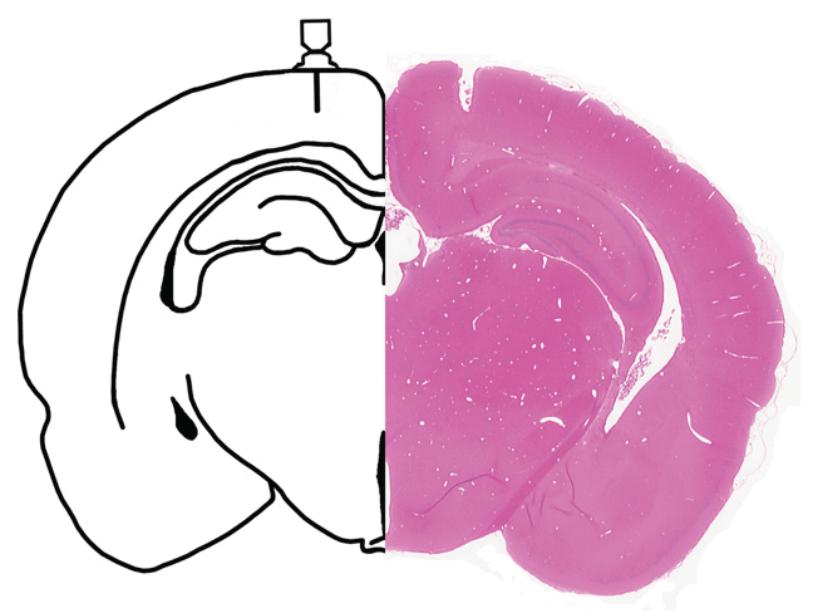

Fig. 1 - Left side of the image shows the placement in a whole $5 \mu \mathrm{m}$ paraffin section stained with HematoxylinEosin. The right side shows a schematic representation of the cannula implantation, rostral to left visual cortex. 


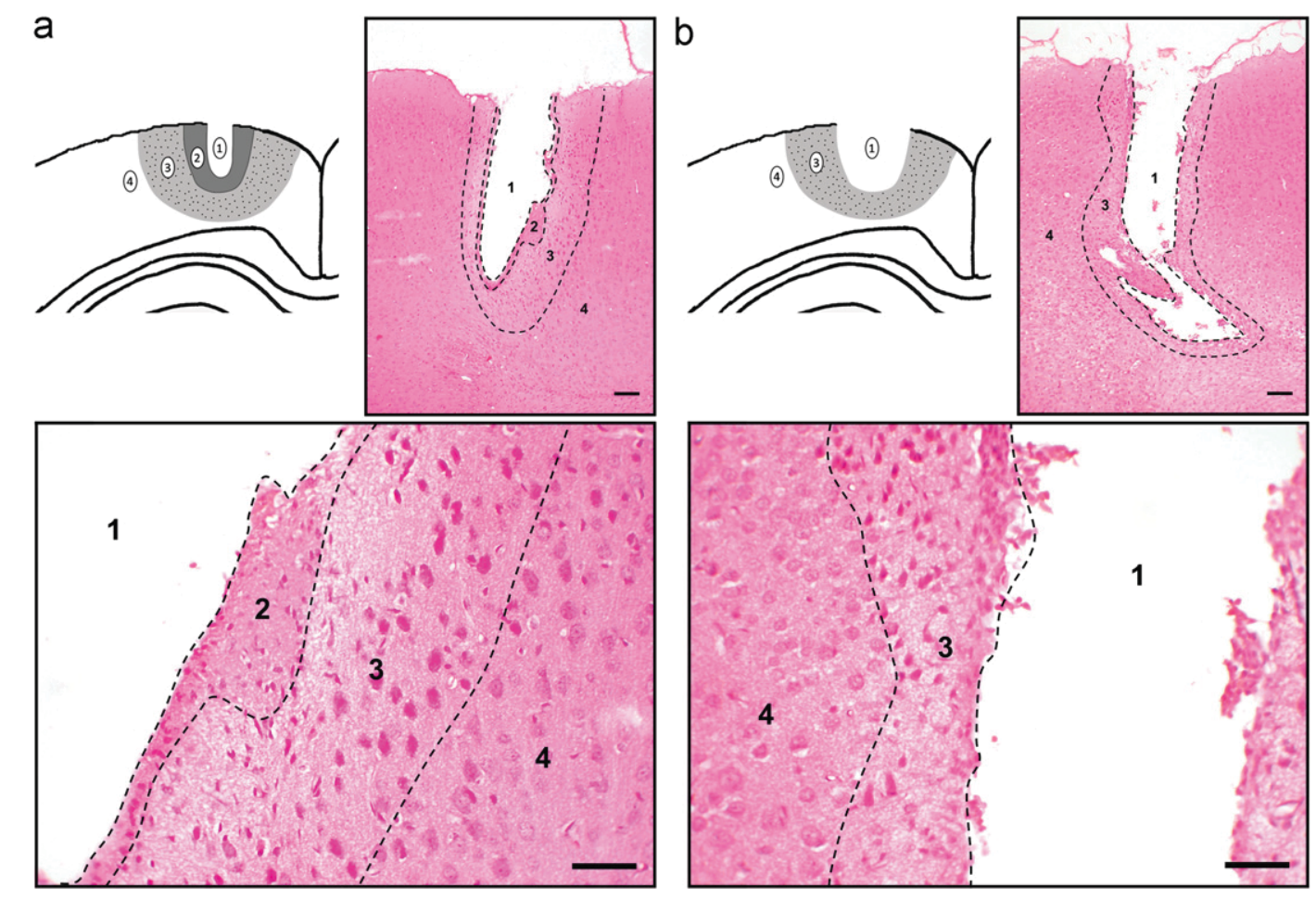

Fig. 2 - Schematic representation of minipump implantation over the Hematoxylin-Eosin stained sections shows that in (a) VEGF-infused rats, the cavity around the cannula (1) is surrounded concentrically by a damaged region (2), a transitional penumbra-like region (3) and undamaged tissue (4). In (b) anti-VEGF-infused rats, the cavity (1) is wider and the damaged tissue disappears. Scale bar is $100 \mu \mathrm{m}$ in lower magnification images and $50 \mu \mathrm{m}$ in a higher magnification images.

red neurons with similar features to those found in ischemic penumbra, therefore it was considered as a penumbra-like region (Fig. 2a and b).

\subsubsection{BBB permeability}

Both vehicle and anti-VEGF-infused groups showed sponginess extending to the subcortical white matter where extravasated plasma proteins were profusely present (Figs. 3e-h, and $\mathrm{m}-\mathrm{p}$ ).

The administration of VEGF induced a lower concentration of plasma proteins in the neuropil around the cannula placement, evoking a lower vascular permeability compared to the other groups. In addition, EBA expression remained present in most of the microvessels, including those near the cannula placement (Figs. 3i-l). In the other hand, anti-VEGFinfused group show fewer EBA positive vessels in the same area (Figs. $3 \mathrm{~m}-$ p).

Extravasated protein reached $552 \mu \mathrm{m}$ medially and laterally from the lesion edge in vehicle infused rats and $535 \mu \mathrm{m}$ in anti-VEGF infused ones, it only reached $44 \mu \mathrm{m}$ when VEGF was infused (1155\% and 1115\% less respectively) (Fig. 3r). The cavity of the cannula track was significantly wider in both the vehicle group $\left(133 \%, 880,000 \mathrm{~m}^{2}\right)$ and the anti-VEGF group $\left(123 \%, 843,000 \mu \mathrm{m}^{2}\right)$ than in the VEGF group $\left(380,000 \mu \mathrm{m}^{2}\right)$ (Fig. 3q).

\subsubsection{Astroglial reaction}

In the same way, GFAP immunohistochemistry revealed a higher positivity in astroglial cells around the cannula placement in VEGF-infused animals compared to either anti-VEGF or vehicle infused animals (Fig. 4). In VEGF-infused rats, a mild astroglial reaction delimits the necrotic tissue from the penumbra area (Fig. 4i-l). Anti-VEGF administration produced a lower GFAP expression than that shown with VEGF administration (Fig. $4 \mathrm{~m}-\mathrm{p}$ ). Immunohistochemistry against VEGF showed a high astroglial expression in VEGF-infused animals (Fig. 4i-l), that was decreased in the vicinity of the lesion in anti-VEGF-infused rats (Fig. $4 \mathrm{~m}-\mathrm{p}$ ). No astroglial reaction was observed in non-operated animals (Fig. 4a-d).

In the vicinity of the lesion, the astrocytic density estimated by the number of GFAP positive astrocytes per $\mathrm{mm}^{3}$ of visual cortex was $22 \%$ higher in VEGF-infused animals and $40 \%$ lower in anti-VEGF infused ones compared to vehicle infused rats. Although no significance was achieved between the vehicle group and either the VEGF or the anti-VEGF infused groups, the difference between anti-VEGF and VEGF was significant (Fig. 4q). In the contralateral cortex, values were very similar with slight, insignificant differences between the 3 groups. Values were significantly lower in the contralateral cortex than in the ipsilateral cortex for all 3 groups (Fig. 4r).

\subsection{Quantitative results in the visual cortex}

\subsubsection{Vascular density}

In non-operated controls, we measured a significant $43 \%$ and $42 \%$ increase in the number of intersections between vessels and grid per $62,500 \mu \mathrm{m}^{2}$ of visual cortex from P18 to P25 in the ipsilateral and contralateral cortex respectively. 

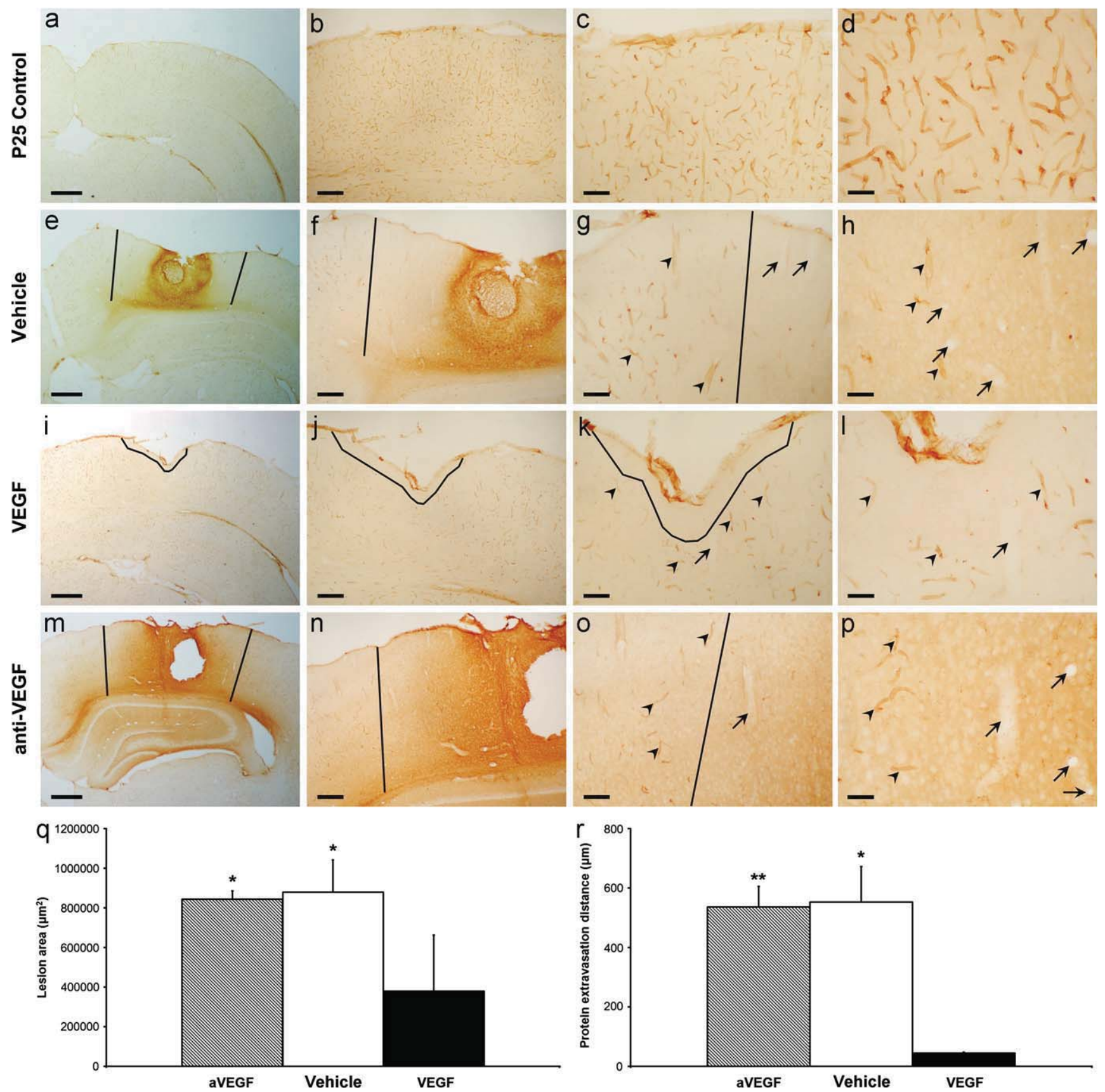

Fig. 3 - EBA and extravasated IgG expression in P25 control rats (a-d), vehicle infused rats (e-h), VEGF infused rats (i-l), and anti-VEGF infused rats $(m-p)$. Lines show the division between EBA positive and EBA negative regions near the cannulae. Arrowheads indicate EBA positive vessels and arrows indicate EBA negative vessels. Scale bar is $600 \mu \mathrm{m}$ in a, e, i, and m; $250 \mu \mathrm{m}$ in b, f, j, and n; $100 \mu \mathrm{m}$ in c, g, k, and o; and $50 \mu \mathrm{m}$ in d, h, l, and p. Comparison of average measurements of (q) lesion area $\left(\mu \mathrm{m}^{2}\right)$ and $(\mathrm{r})$ protein extravasation distance $(\mu \mathrm{m})$ between different experimental groups (anti-VEGF, vehicle and VEGF). Mean \pm standard error. ${ }^{*}$ Shows significance against VEGF-infused group $(p<0.05)$. ${ }^{* *}$ Shows significance against VEGF infused group $(p<0.01)$.

At P25, vascular density was significantly higher in controls than in all the infused groups. Nevertheless, a significant increase was observed from P18 in the three infused groups, being higher when VEGF was infused.

In the ipsilateral hemisphere, the infusion of the vehicle inhibited in part the physiological increase of vascular density during the critical period in the visual cortex, where vascular density was $27 \%$ significantly lower than in noninfused P25 animals although a 29\% increase was recorded compared to P18. Similar data were achieved in anti-VEGFinfused animals, with $29 \%$ fewer vessels were measured than in P25 controls and 26\% more than at P18, both differences being significant. In contrast, animals infused with exogenous VEGF showed values closer to untreated animals, as 
Ipsilateral
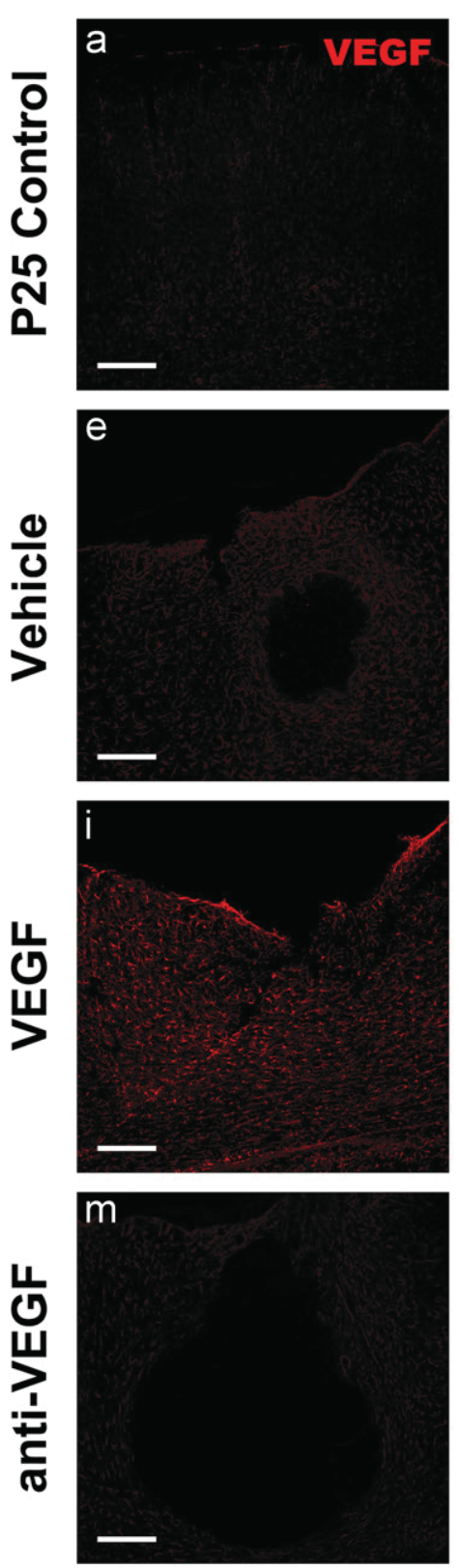

q
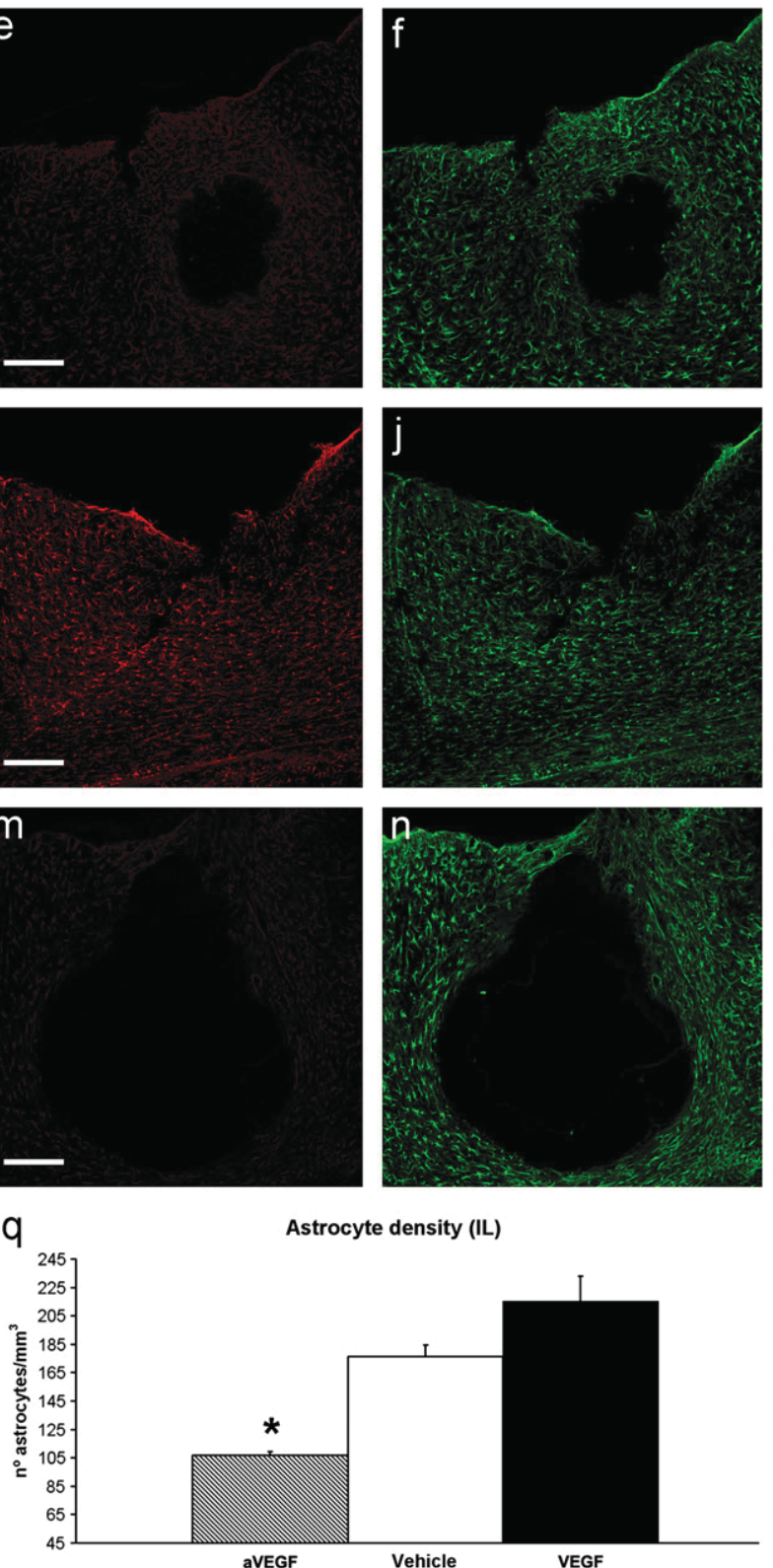
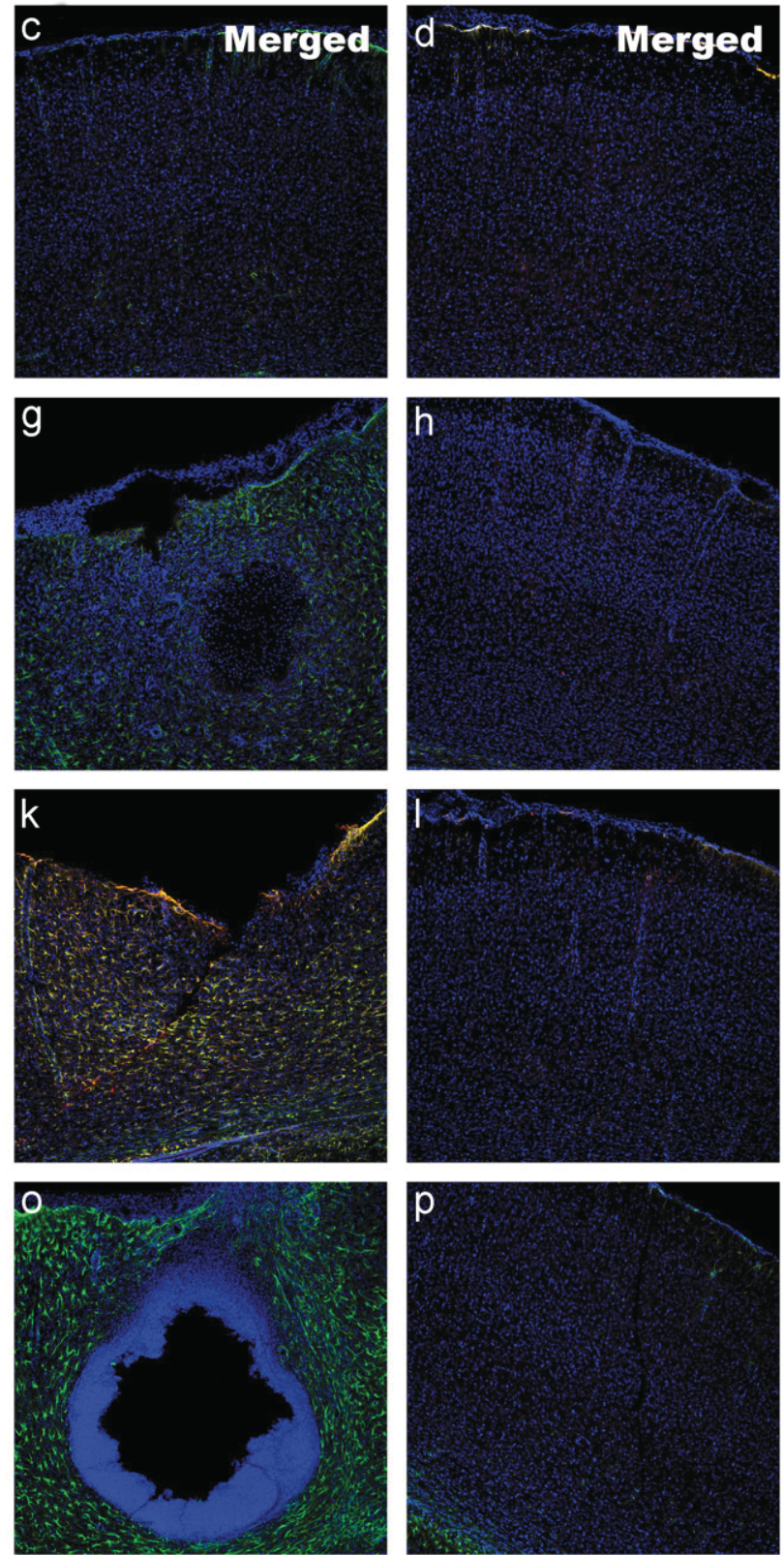

r

Astrocyte density (CL)

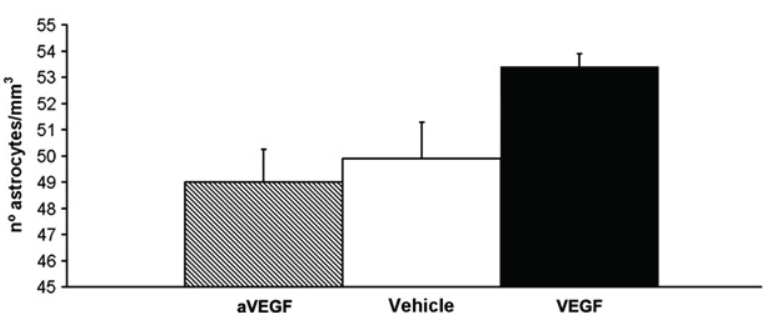

Fig. 4 - Confocal images of immunofluorescence of VEGF (red), GFAP (green), Hoechst (blue) and merged to show the expression of VEGF and GFAP near the cannulae placement and in the contralateral cortex of P25 control rats (a-d), vehicleinfused rats (e-h), VEGF infused rats $(i-1)$ and anti-VEGF infused rats $(m-p)$. Scale bar is $200 \mu m$. Comparison of average measurement of astrocyte density in the Ipsilateral (IL) and Contralateral (CL) cortices. Horizontal axes show different experimental cohorts (VEGF-, anti-VEGF-, vehicle infused rats). Vertical axes show number of GFAP positive cells per mm $^{3}$ near the cannulae placement. Mean \pm standard error. *Shows significance against VEGF-infused animals. (For interpretation of the references to color in this figure legend, the reader is referred to the web version of this article.) 
vascular density increased a significant $46 \%$ from P18. Nevertheless, values did not reach control values, as they were still significantly $18 \%$ lower than P25 controls. On the other hand, VEGF infused rats showed significantly more vessels than anti-VEGF infused (15\%) and vehicle infused (13\%) ones, and no difference between vehicle and anti-VEGF was observed (Fig. 5a).

The same behavior occurred in the contralateral cortex, as comparison against non-operated P25 rats was 30\% lower in vehicle infused animals and 23\% lower in anti-VEGF-infused ones. In VEGF-infused animals, the difference compared to untreated controls lacked significance, being only $6 \%$ lower. For the three groups significant increases were measured from P18, being $22 \%$ in vehicle infused rats, $36 \%$ in anti-VEGF infused ones and $65 \%$ in VEGF-infused group. Furthermore, VEGF-infused group presented a higher vascular density than vehicle-(34\%) and anti-VEGF-infused (21\%) groups, being statistically significant. We have to mention that in this case, the difference between anti-VEGF and vehicle was unsignificant (Fig. 5a)

a

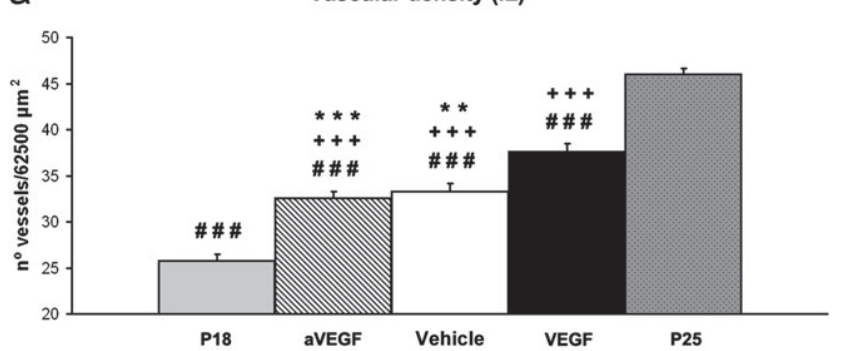

b
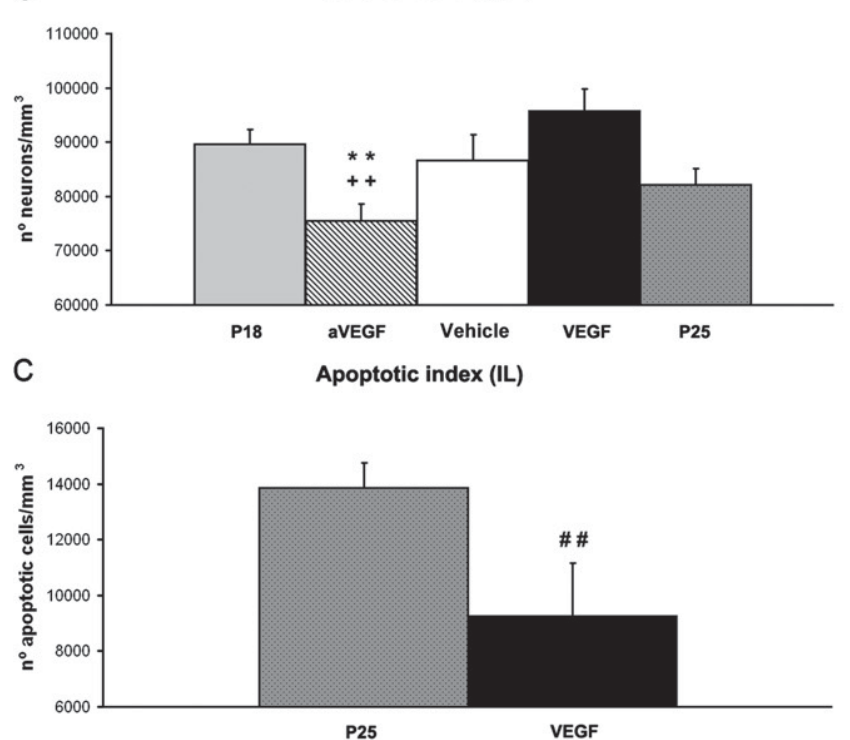

\subsubsection{Neuronal density}

There was a non-significant 9\% decrease in neuronal density, measured as the number of NeuN positive neurons per $\mathrm{mm}^{3}$, from P18 to P25 in non-operated rats. This trend was similar in all groups except in anti-VEGF infused rats that showed a significant $13 \%$ decrease compared to P18. Neuronal density was $5 \%$ higher in vehicle infused rats compared to nonoperated P25 controls, 16\% higher in VEGF-infused rats and $8 \%$ lower in anti-VEGF infused ones. Nevertheless, none of the differences were significant, although the values between VEGF and anti-VEGF were significantly $27 \%$ lower in the latter (Fig. 5b).

In the contralateral cortex, similar results were found. Neuronal density was 9\% lower at P25 than at P18 in the non-operated control groups. Values were higher in both anti-VEGF-infused (4.5\%) and in vehicle infused (5\%) groups compared to P25 non-operated. In contrast, VEGF-infused animals showed 24\% more neurons than P25 non-operated controls, the difference being significant in this hemisphere. We have to note that for VEGF-infused animals, values were
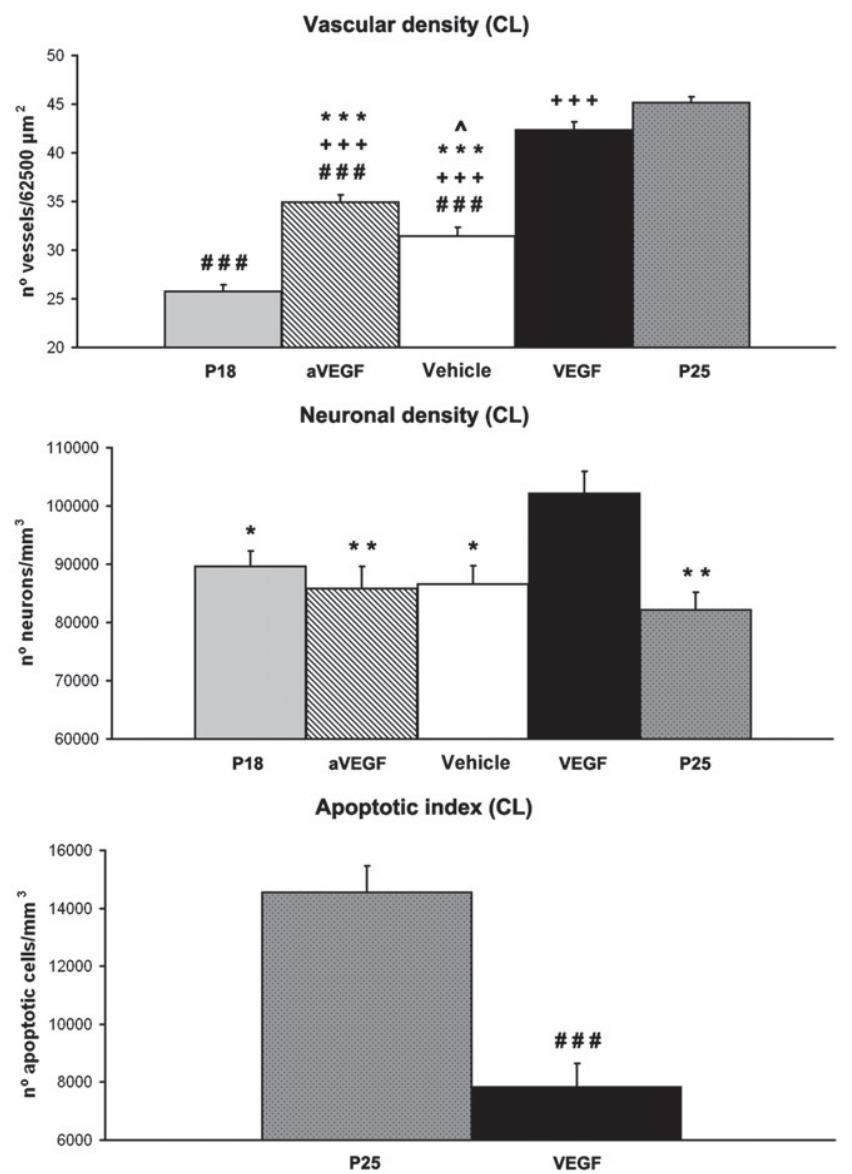

Fig. 5 - Comparison of average measurements of vascular, neuronal and apoptotic densities in the Ipsilateral (IL) and Contralateral (CL) cortices. Horizontal axes show different experimental cohorts (P18 rats, anti-VEGF-infused rats, vehicleinfused rats, VEGF-infused rats and P25 control rats). Vertical axes show (a) number of vessels per $62,500 \mu \mathrm{m}^{2}$ of primary visual cortex, (b) number of NeuN positive cells per $\mathrm{mm}^{3}$ of layer IV of primary visual cortex, (c) number of TUNEL positive apoptotic cells per $\mathrm{mm}^{3}$ of layer IV of primary visual cortex. Mean \pm standard error. \#\# Shows significance against P25 control rats $(\boldsymbol{p}<0.01)$. \#\#\# Shows significance against P25 control rats $(\boldsymbol{p}<0.001)$. * Shows significance against VEGF-infused rats $(\boldsymbol{p}<0.05) .{ }^{* *}$ Shows significance against VEGF-infused rats $(\boldsymbol{p}<0.01){ }^{* * *}$ Shows significance against VEGF-infused rats $(p<0.001)$. + Shows significance against P18 rats $(p<0.01)$. + Shows significance against P18 rats $(p<0.001){ }^{\wedge}$ Shows significance against anti-VEGF-infused rats $(p<0.05)$. 


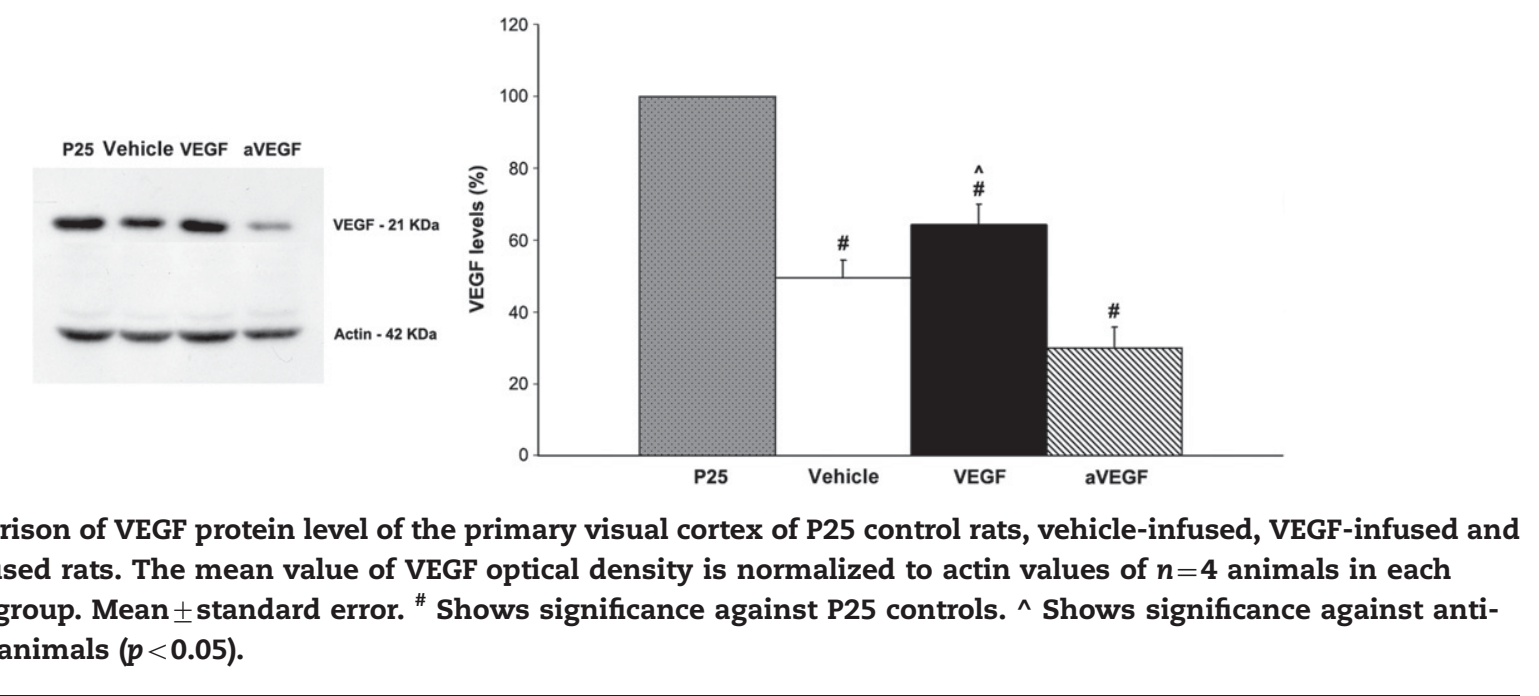

even higher at P25 than in non-infused P18 rats in both hemispheres, both being significant in the contralateral cortex (14\%). On the other hand, VEGF-infused groups showed a significantly higher neuronal density compared to anti-VEGF infused (19\%) and vehicle-infused (18\%) groups (Fig. 5b).

\subsubsection{Apoptotic cell density}

To elucidate the quantitative relevance of apoptosis in the increased neuron density found in VEGF-infused animals at P25, we measured the number of apoptotic cells per $\mathrm{mm}^{3}$. In this experiment a $33.2 \%$ lower density was found in VEGFinfused rats compared to P25 non-operated controls in the ipsilateral cortex and $46.1 \%$ lower in the contralateral, being in both cases statistically significant (Fig. 5c).

\subsubsection{VEGF western blot}

Immunoblot analysis revealed that immunoreactive bands corresponding to VEGF displayed a stronger expression in the control group than in the experimental groups. Quantification of the bands revealed that whereas VEGF expression was a $36 \%$ lower in VEGF-infused rats than in non-operated controls, it was $51 \%$ lower in vehicle-infused rats and $70 \%$ lower in anti-VEGF-infused ones. All differences were significant between non-operated controls and infused rats as well as between VEGF and anti-VEGF-infused animals. The difference between vehicle-infused and anti-VEGF infused rats was $15 \%$, but unsignificant (Fig. 6).

\section{Discussion}

Our main result suggests that the placement of the cannula induces a surgical brain trauma with consequences in some events linked to the maturation of the visual cortex, such as the increase in vascular density. These changes occur even if the tissue is not directly affected, as in the contralateral hemisphere, where the effects of the lesion are reverted by VEGF. Contralateral effects are suggestive of an ipsilateral and contralateral diaschisis process (Von Monakow, 1914; Andrews (1997)). The infusion of VEGF contributes not only to reducing the effects of the lesion, but also to diminishing the physiological apoptosis in the developing rat visual cortex in the contralateral cortex, expressed by a lower density of TUNEL-marked apoptotic cells. In addition, despite its role as a permeability factor, VEGF administration maintains a degree of BBB integrity, being less remarkable the edema histopathological features, such as sponginess and plasma protein exudates, than in the other infused rats. VEGF infusion also preserves the core of the lesion, apparently due to an increase in the astroglial reaction. The evidence of a traumatic penumbra similar to the ischemic one, with damaged but still viable neural tissue is becoming of great importance in order to focus on therapeutic strategies (Cunningham et al., 2005; Khan et al., 2009). Our results suggest that VEGF administration induces a reduced penumbra region with better preservation of vascular and neuronal integrity.

\subsection{Cortical changes around the infusion-produced injury}

\subsection{1. $B B B$}

VEGF was initially described as a vascular permeability factor, and one of the main effects of VEGF intracortical administration is the increase in BBB permeability in adults (Dobrogowska et al., 1998; Fischer et al., 2002; Krum et al., 2002). Previous studies have posited EBA as a specific marker for the $\mathrm{BBB}$ in rats, linking its expression with the functionality of the blood-brain barrier (Lin et al., 2001; Norsted et al., 2008) since a decrease in EBA positivity has been reported in pathological conditions where the administration of an antiEBA antibody resulted in increased permeability of brain microvessels (Ghabriel et al., 2000; Ghabriel et al., 2002). Nevertheless, most of this research has been performed in adults at an age at which, under normal conditions, physiological VEGF levels are quite low. In addition, our previous research has shown that at the beginning of the critical period there is a significant percentage of cortical vessels with a BBB that does not seem to be fully mature, as $27 \%$ of brain capillaries lack EBA positivity (Argandoña et al., 2005).

Our results show that, it has already been mentioned above the paradoxal effect of VEGF infusion contributing to a decrease in protein extravasation compared to vehicle or aVEGF infused animals, in addition to this finding, numerous 
microvessels show EBA positivity close to the cannula placement.

These results are in accordance with previous findings reporting that the blockade of VEGFR-2 after a TBI leads to increased lesion area and increased cellular death (Skold et al., 2006). A previous study suggested that damage to neurons precedes leakage of the blood-brain barrier (Albayrak et al., 1997), hence, the neuroprotective effects of VEGF could contribute to a lower injury of the neural tissue that would lead to a better preservation of BBB integrity. On other hand, as some authors have reported, the balance between beneficious and deleterious effects of VEGF in brain diseases is highly dependent on the dose, the time window and the way of administration (Herz et al., 2012; Yang et al., 2012). Whereas systemic administration showed detrimental effects including increased permeability of the $\mathrm{BBB}$, local administration reduced or unchanged edema and protein extravasation (Hermann and Zechariah, 2009). The dose that we have administered in the current work and the route used has proven to promote angiogenesis and neuroprotection with a better preservation of the BBB integrity, possibly by a direct action on the three elements of the neurogliovascular unit.

\subsubsection{Astroglial reaction}

The central nervous system reacts to different types of lesions with reactive astrogliosis (Duchen, 1992; Pekny and Nilsson, 2005; Sofroniew, 2009) characterized by astrocyte hyperplasia, hypertrophy, and increased expression of the astrocyte-specific intermediate filament protein, glial fibrillary acidic protein (GFAP). Some authors have shown that the infusion of VEGF induces an astroglial response after the injury, that is lowered by blocking endogenous VEGF (Krum et al., 2002; Krum and Khaibullina, 2003; Mani et al., 2005). These results have also been reproduced in vitro (Rosenstein et al., 2003; Mani et al., 2005). Our results confirm these findings, as we have found an increase in GFAP expression in VEGF-infused animals in the surroundings of the lesion. On the other hand, these authors reported a decrease in the astroglial response when VEGF was inhibited in adults. In contrast, our results only show this kind of response in the very near vicinity of the lesion. This finding could be related to the intense endogenous VEGF secretion that occurs in the rat visual cortex at the 4 th postnatal week, something that is almost completely lacking in adults. In fact, previous studies showed that the infusion of anti-VEGF was unable to entirely block the endogenous secretion of VEGF that occurred in response to the lesion (Krum and Khaibullina, 2003).

\subsection{Effects on the visual cortex}

\subsubsection{Vascular density}

We have previously reported that the main quantitative experience-induced vascular changes occur at the beginning of the critical period, where some authors have dated the peak of the neuronal critical period (Argandoña and Lafuente, 1996, 2000; Berardi et al., 2000; Argandoña and Lafuente, 2002; Argandoña et al., 2005). Our previous results suggest that the increase of experience induces an increase in vascular density mediated by a peak in the secretion of VEGF. This peak occurs at the 4 th postnatal week, shortly after the end of the minipump placement (Bengoetxea et al., 2008). The implantation-produced lesion induces a significantly lower increase of vascular density, which is one of the changes related to the postnatal maturation of the visual cortex (Argandoña and Lafuente, 1996, 2000, 2002; Argandoña et al., 2005; Bengoetxea et al., 2008). Several authors have reported that brain injuries in developing animals generate a delay in plasticity without gross morphological damage (Prins et al., 1996; Fineman et al., 2000; Adelson et al., 2001; Argandoña et al., 2006; Gurkoff et al., 2006).

We have found similar values when infusing vehicle or when blocking VEGF with an antibody. In contrast, some authors have previously reported that blocking VEGF with an antibody induces a higher degree of tissue affectation due to the lack of local response induced by endogenous VEGF (Krum and Khaibullina, 2003). This apparent discrepancy could be due to the fact that previous studies have been done in adults, in which, in normal conditions, there is a very scarce secretion of VEGF, as we have previously reported. In contrast, the infused anti-VEGF may not be enough to neutralize the peak of the endogenous VEGF secretion that occurs at the 4 th postnatal week. On the other hand, VEGF infusion rescues in part the vascular increase, suggesting that despite the lack of increased permeability, there is still a protective response against the consequences of the injury. In addition, VEGF infusion rescues the increase of vascular density in the contralateral cortex, as values are similar to non-operated controls.

\subsubsection{Neuronal density}

In control animals, there is a decrease in neuronal density that can be linked to the physiological apoptosis that occurs in the sensory system when the non-functioning neurons die (Ortuzar et al., 2011). Our results show a trend towards an increase in the neuronal density from P18 to P25 in VEGFinfused rats. Although no significant difference has been shown in the ipsilateral cortex, the increase in the contralateral cortex from P18 to P25 is statistically significant. We have no data to support the idea that there is cortical neurogenesis in the visual cortex due to the infusion of VEGF, as occurs in vitro or in other regions (Palmer et al., 2000; Louissaint et al., 2002; Maurer et al., 2003; Rosenstein et al., 2003; Sun et al., 2003). Previous studies have reported that the administration of VEGF reduces the increase of apoptosis in experimental spinal cord injury (Widenfalk et al., 2003). In agreement with them, we also suggest that VEGF infusion rescues neurons from physiological apoptosis. As has been reported, NeuN is a soluble nuclear protein that is widely used as a marker for neurons to mark the whole population. Some authors have investigated the correlation between the loss of NeuN antigenicity and the neuronal loss sustained after brain injury. They found that a significant number of neurons lose their positivity but preserve their integrity, although they may no longer be viable (Unal-Cevik et al., 2004). Our results point towards that direction. The increase of neuronal density could therefore be due to a phenomenon of neurorescue of cells that could have lost their NeuN antigenicity. Our results on apoptotic quantification support this hypothesis, as VEGF-infused animals have a significantly lower density of apoptotic neurons. 
In contrast, the administration of anti-VEGF produces a significant decrease from P18 only in the ipsilateral side, not being significant compared to P25 controls. In this group, the higher degree of tissue damage that appears in this group in the vicinity of the lesion could be responsible for the increased neuronal loss far from the lesion core.

\subsubsection{VEGF levels}

Our results show that the suggested diminished activity in the primary visual cortex due to the minipump implantation is also reproduced in the VEGF levels, as values were significantly lower for all operated animals. As we reported previously (Bengoetxea et al., 2008), the increase in vascular density during the critical period of the visual cortex runs parallel to the increase of VEGF levels. Our results show that although the infusion of VEGF does not reach control values, it is still significantly higher than in anti-VEGF-infused animals, this trend being similar to the trend in vascular or neuronal density quantifications. Although the difference with respect to vehicle is not statistically significant, the trend is in agreement with the effects of VEGF infusion in morphological results on vascular, neuronal and astrocytic densities. Therefore, our results show a link between an increase in VEGF expression and angiogenic, neuroprotective and astrocytic effects of VEGF infusion that are accompanied by the preservation of the BBB function.

\subsubsection{Contralateral effects}

Results show that for all of the parameters studied, there is a similar reaction in the contralateral cortex where there is no direct effect of the lesion. In some cases, results were not significant in the ipsilateral hemisphere but were significant in the contralateral one. Differences between groups were slightly higher in the contralateral cortex. As there is no direct arrival of the infused VEGF to the contralateral visual cortex, effects could be related to the phenomenon called diaschisis. Diaschisis was defined as the sudden inhibition of function produced by an acute focal disturbance in a portion of the brain at a distance from the original site of injury, but anatomically connected with it through fiber tracts (Von Monakow, 1914; Andrews, 1997). The effects of the lesion on the development of the cortex are thus noticed not only in the surroundings of the lesion, but also in a distant ipsilateral part and also in the contralateral cortex and molecular recovery mechanisms operate also far from the damaged zone (Hu et al., 2011). In agreement with this, some authors have demonstrated in rodents the neurovascular coupling between the cortices of both hemispheres regarding changes of neuronal activity (Hoffmeyer et al., 2007). They have also reported that cerebral metabolism or blood flow is activated by interhemispheric connections. Our results suggest that these hemodynamic responses also have a neuronal and vascular anatomical correlation, as the studied parameters have the same trend in both hemispheres, although there is no cannulainduced injury in the contralateral cortex.

Also supporting the findings of global effects of local injuries, some authors have reported that the effects of localized cortical stroke compromise not only the surrounding of the lesion, but also the whole hemisphere or the intact contralateral hemisphere (Greifzu et al., 2011). As the interaction of both intact hemispheres is required for the normal plasticity processes (Murase et al., 2004), the inhibitory influence of the intact one could explain our results, which show a higher response in the intact hemisphere compared to the injured one when trophic factors are administered. Similar results have been found by the local administration of VEGF in a model of ischemia, when VEGF promotes plasticity in the contralateral hemisphere by regulating plasticity factors such as ephrins (Reitmeir et al., 2012; Herz et al., 2012).

\subsubsection{Neurogliovascular unit}

Closely involved in the explanation of this phenomenon could be the emerging concept of neurovascular unit (NVU) has recently emerged, proposing that neurons, glia and vascular components must all be studied in an integrated context (Hawkins and Davis, 2005; Lok et al., 2007; del Zoppo, 2010; Lecrux and Hamel, 2011). Some authors postulate that neuroprotection itself is not sufficient for reverting brain disorders. They have hypothesized that complete neuroprotection must involve glioprotection as well as vasculoprotection (Bastide et al., 2007; Lok et al., 2007; Vangilder et al. (2011)). Our results show that the infusion of VEGF as a neuroprotective strategy produces effects in most of the NVU components: neurons, astrocytes and the vascular network. In this line, molecules like VEGF, that affect both the neural and the vascular cell processes have recently been termed angioneurins (Zacchigna et al., 2008; Lafuente et al., 2012; Argandoña et al., 2012).

In conclusion, the behavior of brain lesions in developing brains is substantially different and more complex than in adults and consequences could persist throughout the entire life. The administration of angioneurins such as VEGF could be an effective neurorestorative procedure in various brain disorders, as they act on the three components of the NVU. VEGF has often been described as a double-edged sword due to its beneficial and detrimental effects on brain pathologies, so this factor can have an important therapeutic value if correctly applied. Our results show that the local administration of neurorestorative molecules could also have beneficial effects in both hemispheres. Future studies are required to determine the functional and behavioral implications of the neurorescue mediated by VEGF.

\section{Experimental procedure}

\subsection{Animals and surgical procedures}

Experiments were performed on Long-Evans rats prior to the beginning of the critical period (P18). Alzet osmotic minipump (Mod. 1007 D, Alzet, Cupertino, CA) with a delivery rate of $0.5 \mu \mathrm{l} / \mathrm{h}$ during one week, connected via polyethylene tubing to a brain infusion kit (Mod. Alzet Brain Infusion Kit III, Alzet) were used to infused substances to rat cortex.

Animals were anaesthetized with Avertin $(1 \mathrm{ml} / 100 \mathrm{~g})$, and a sagittal incision was made midway between the eyes. First, the skin was retracted and then the periostium. A subcutaneous pocket was made in the animal's back into which the osmotic minipump was placed. Minipumps were connected 
to a brain infusion kit that was implanted $1 \mathrm{~mm}$ lateral and rostral to lambda, leaving primary visual area 17 intact and reaching middle cortical layers (Fig. 1). The brain infusion kit was fixed to the skull with cyanoacrylate. Operating time was around $25 \mathrm{~min}$. With this position of the cannula, diffusion reaches area 17 as indicated by previous studies (Lodovichi et al., 2000).

Five animal groups were used

(a) P18 control group: un-operated rats $(n=14)$.

(b) P25 control group: un-operated rats $(n=14)$.

(c) Vehicle group: PBS $0.1 \mathrm{M}$ infusion was used as a VEGF/ anti-VEGF control $(n=14)$.

(d) VEGF group: VEGF (Ref: sc-4571, Santa Cruz Biotechnology, $25 \mathrm{ng} / \mathrm{ml}$, diluted in PBS $0.1 \mathrm{M})(n=14)$.

(e) Anti-VEGF group: anti-VEGF (Ref: sc-152, Santa Cruz Biotechnology, $25 \mu \mathrm{g} / \mathrm{ml}$, diluted in PBS $0.1 \mathrm{M})(n=14)$ was administered to study the effects of endogenous VEGF inhibition.

All animals had access to food and water ad libitum. Every effort was made to minimize animal suffering and to reduce the number of animals use. All animal experiments were performed in accordance with the European Community Council Directive of 24 November 1986 (86/609/EEC) and approved by the Ethics Committee for animal welfare (CEBA) of the University of the Basque Country (Ref: CEBA/80/2010).

\subsection{Fixation and tissue processing}

Minipumps were left in position for one week, and afterwards, the rats were anaesthetized with $6 \%$ chloral hydrate. After anesthesia, the cannulae were removed and the animals were transcardially perfused with a fixative containing $4 \%$ paraformaldehyde in $0.1 \mathrm{M}$ Phosphate Buffer. Perfusion was carried out at a constant pressure of $20 \mathrm{~mm} \mathrm{Hg}$. Following perfusion, the brains were stored overnight at $4{ }^{\circ} \mathrm{C}$ in fresh fixative.

The following day, a thick block of occipital cortex containing the visual area, including the cannula placement, was coronally cut with a Rodent Brain Matrix (Electron Microscopic Sciences, USA), rinsed in cold PBS for $4 \mathrm{~h}$ and embedded in paraffin (thin sections) or cryopreserved in 30\% sucrose (thick sections). 5 brains per experimental group were processed by each method. The paraffin block was serially cut with a microtome into sections of $5 \mu \mathrm{m}$ and mounted on slides coated with APES (3-aminopropyltriethoxylane). The frozen block was cut at $50 \mu \mathrm{m}$ with a cryotome and serially collected sections were kept in PBS to be immunohistochemically processed using the free-floating method.

\subsection{Histology}

Conventional Hematoxylin-Eosin stain was performed with paraffin sections to identify the extension of the cavity and the general damage of the tissue. Samples were de-paraffinised from the tissue through xylene immersion and was rehydrated. Tissue was stained with hematoxylin solution and then in eosin. Tissue was hydrated, and covered.

\subsection{Immunohistochemistry}

Thick cryotome sections were immunohistochemically processed for Endothelial Barrier Antigen EBA (Ref: SMI-71, Sternberger Monoclonals, working dilution 1:2000), GFAP (Ref: G-3893, Sigma-Aldrich, working dilution 1:400) and NeuN (Ref: MAB377, Chemicon International Inc, working dilution 1:400). Briefly, sections were washed in 0.1 M PBS, incubated with $4 \% \mathrm{H}_{2} \mathrm{O}_{2}$ /methanol for 20 min in order to block endogenous peroxidase activity and were incubated with blocking solution (10\% BSA in $0.1 \mathrm{M} \mathrm{PBS})$ for $1 \mathrm{~h}$. Then sections were incubated overnight at $4{ }^{\circ} \mathrm{C}$ with primary antibody in 5\% BSA in 0.1 M PBS containing 0.3\% Triton X-100. The following day, sections were washed in $0.1 \mathrm{M}$ PBS and incubated with biotinylated secondary antibody (Elite $A B C$ kit, Vector Laboratories, USA) in 5\% BSA in 0.1 M PBS containing $0.3 \%$ Triton $\mathrm{X}-100$. The immunohistochemical reaction was revealed by the avidin-biotin complex using diaminobenzidine as a chromogen. Sections were mounted on slides coated with APES (3 aminopropyltriethoxylane), dehydrated and covered.

IgG extravasation was detected in the same sections processed for EBA immunohistochemistry. As the biotinlylated anti-mouse IgG used as secondary antibodies have a $12 \%$ cross reactivity for rat IgGs, the reaction allow us to visualize in the same section the positivity of the EBA and the degree and extension of blood protein extravasation, giving a comprehensive picture of the BBB integrity.

\subsection{Double immunofluorescence labeling}

Double immunofluorescence was carried out on free-floating sections. Sections were washed in $0.1 \mathrm{M}$ PBS and were incubated with blocking solution (10\% BSA in $0.1 \mathrm{M}$ PBS) for $1 \mathrm{~h}$ followed by overnight incubation with a cocktail of primary antibodies in 5\% BSA in $0.1 \mathrm{M}$ PBS containing $0.3 \%$ Triton X-100. The antibodies used were polyclonal rabbit antiVEGF (Ref: sc-152, Santa Cruz Biotechnology Inc, working dilution 1:200) and monoclonal mouse anti-GFAP (Ref: G-3893, Sigma-Aldrich, working dilution 1:400). After rinsing, sections were incubated for $2 \mathrm{~h}$ with Alexa 568 goat anti-rabbit IgG (Ref: T-6778, Invitrogen, working dilution 1:400) and Alexa 488 goat anti-mouse IgG (Ref: F-9137, Invitrogen, working dilution $1: 400$ ) in $5 \%$ BSA in $0.1 \mathrm{M}$ PBS containing $0.3 \%$ Triton X-100. Sections were then incubated in Hoechst solution for $10 \mathrm{~min}$ and they were rinsed, mounted on gelatin-coated slides, and cover-slipped in aqueous medium. Also included in each staining run were negative controls in which the primary antibody was omitted. Images were acquired for confocal fluorescence microscopy with an Olympus Fluoview FV500 confocal microscope using sequential acquisition to avoid overlapping of fluorescence emission spectra.

\subsection{Histochemistry}

Thick sections $(50 \mu \mathrm{m})$ were washed twice in Tris Maleate Buffer (TMB) 0.1 M (pH 6), acetyl cholinesterase was inhibited 
in a BW284CSl (1,5-bis(4-allyldimethylammoniumphenyl)pentan-3-one dibromide) $0.05 \mathrm{M} 20 \mathrm{~min}$ bath and sections were incubated overnight in the following incubation solution: Butyryl thiocholine iodide $1 \mathrm{mg} / \mathrm{ml}, 5 \%$ sodium citrate $0.1 \mathrm{M}, 10 \%$ copper sulfate $30 \mathrm{mM}, 10 \%$ BW284CSl $0.05 \mathrm{mM}$, $10 \%$ potassium ferricyanide $5 \mathrm{mM}$ and $65 \%$ TMB $0.1 \mathrm{M}$. The next day, sections were washed in TMB, mounted, dehydrated and covered.

\subsection{Terminal deoxynucleotidyl transferase mediated dUTP-biotin nick end labeling (TUNEL)}

Samples were de-paraffinised as previously described and then subjected to proteinase $\mathrm{K}$ (1:100 in Tris Buffer $\mathrm{pH} 8)$ digestion (10 $\mathrm{min}$ at room temperature). Endogenous peroxidase activity was blocked with $4 \% \mathrm{H}_{2} \mathrm{O}_{2}$ /methanol for $20 \mathrm{~min}$.

The nuclear DNA fragmentation was identified by TUNEL assay using the Klenow-FragEL DNA Fragmentation detection kit (Ref: QIA21, Oncogene Research Products) following the manufacturer's protocol. The TUNEL signal was revealed by the avidin-biotin complex using DAB as a chromogen. Sections were lightly counterstained with Hematoxylin and finally dehydrated and covered.

\subsection{Morphometric procedures}

Cannula implantation area: cannula produced lesion (area), protein extravasated distance and astrocytic density were measured with the aid of the Mercator Image Analysis System (Explora Nova, La Rochelle, France). Lesion area and protein extravasation distance were measured in EBA immunostained sections. Astrocytic density was measured on GFAP immunohistochemistry sections by the optical dissector method, with the aid of the Mercator Image Analysis system (Explora Nova, La Rochelle, France). For this purpose, probes of $50 \times 50 \mu \mathrm{m}^{2}$ separated by $120 \mu \mathrm{m}$ were launched into a previously delimited region that corresponds to the damaged area around the lesion produced by the cannula implantation. Positive cells were counted if found to be present inside the probe and if they did not touch the forbidden $X$ and Y axes.

5 animals and 4 histological sections per animal were used for each experimental group.

Visual cortex: the number of vessels per area was measured by the intersection method. A count was made of the number of intersections between vessels and an overlying grid. The grid was a square whose line length was $250 \mu \mathrm{m}$ divided horizontally and vertically every $50 \mu \mathrm{m}$; therefore, total surface was $62,500 \mu \mathrm{m}^{2}$. The grid was randomly placed between cortical layers III and V, ensuring that layer IV was included. Neuronal and apoptotic densities were measured by the optical dissector method, with the aid of the Mercator Image Analysis system (Explora Nova, La Rochelle, France) on NeuN immunohistochemistry and TUNEL histochemistry respectively. Measurements were made into a previously delimited area corresponding to layer IV of the primary visual cortex. In the quantification of apoptotic density, cells expressing any degree of positivity (light to dark brown staining) were considered positive only if they accomplished the morphological features of apoptotic nuclei, such as intense nuclear staining indicating chromatin condensation, membrane blebbing and presence of apoptotic bodies (Fig. 7).

5 animals and 10 histological sections per animal were used for each experimental group, with a minimum of 10 measurements per section.

\subsection{Sample preparation for western blotting}

4 animals per group were used to western blotting. Primary visual cortices from both hemispheres were excised from decapitated anesthetized rats. The two hemispheres were pooled and the tissue was manually homogenized at $4{ }^{\circ} \mathrm{C}$ with $200 \mu \mathrm{l}$ of homogenization lysis buffer containing $10 \mathrm{mM}$ PB (pH 7.4), $5 \mathrm{mM}$ ethylenediaminetetraacetic acid, $5 \mathrm{mM}$ ethyleneglycol-bis(2-aminoethylether) $\mathrm{N}, \mathrm{N}, \mathrm{N}^{\prime}, \mathrm{N}^{\prime}$-tetraacetic acid, $1 \mathrm{mM}$ dithiotreitol, and the protease inhibitor cocktail (Ref: P8340, Sigma-Aldrich). The homogenate was incubated for $30 \mathrm{~min}$ on ice, centrifuged at $13,000 \mathrm{rpm}=15500 \mathrm{~g}$ for $15 \mathrm{~min}$ at $4{ }^{\circ} \mathrm{C}$, and the supernatant was collected and used as soluble protein extract. Protein concentrations were determined using Bio-Rad Protein Assay reagent (Ref: 500-0006, Bio-Rad Laboratories SA), with BSA as standard.

\subsection{Western blot analysis}

Protein $(10 \mu \mathrm{g})$ was boiled at $100{ }^{\circ} \mathrm{C}$ in sodium dodecyl sulfate sample buffer for $5 \mathrm{~min}$, loaded onto a $12.5 \%$ polyacrylamide gel, and separated by electrophoresis (110 V for $90 \mathrm{~min}$; MiniProtean 3 Electrophoresis Cell, Bio-Rad Laboratories SA). Samples were transferred for $3 \mathrm{~h}$ at $60 \mathrm{~V}$ to nitrocellulose
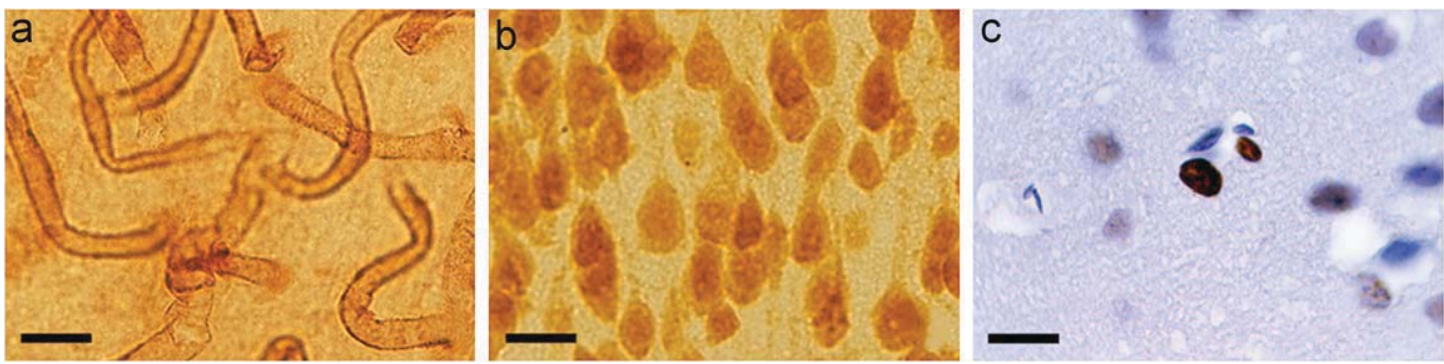

Fig. 7 - Images taken from the primary visual cortex to show the samples used for quantification. (a) Vascular density was quantified on thick sections stained by butyryl cholinesterase histochemistry. (b) Neuronal density was quantified on thick sections processed for NeuN immunohistochemistry. (c) Apoptotic cell density was quantified on thin sections processed by TUNEL histochemistry. Scale bar is $20 \mu \mathrm{m}$. 
membrane (Ref: RPN3032D, Amersham Biosciences Europe). This was then blocked for $2 \mathrm{~h}$ in $5 \%$ nonfat milk in TBS-T buffer (10 mM Tris-HCl pH 7.6, $150 \mathrm{mM} \mathrm{NaCl}$, and 0.1\% Tween20). Afterward the membranes were incubated at $4{ }^{\circ} \mathrm{C}$ with the primary anti-VEGF antibody (Ref: sc-152, Santa Cruz Biotechnology Inc, working dilution 1:500). After washes in TBS-T buffer, the blots were incubated for $2 \mathrm{~h}$ with horseradish peroxidase-conjugated secondary antibodies (Ref: A-6154, Sigma-Aldrich, working dilution 1:2000). Following washing, the immunoblots were detected using an enhanced chemiluminescent Western blotting detection reagent (Ref: RPN2106, Amersham Biosciences Europe). To ensure equal loading of samples, membranes used to measure VEGF protein expression were stripped in stripping buffer ( $100 \mathrm{mM}$ glycine, $\mathrm{pH}$ 2.3) at $55{ }^{\circ} \mathrm{C}$ for $30 \mathrm{~min}$ and then probed with anti-Actin antibody (Ref: A-2066, Sigma-Aldrich, working dilution 1:2000).

\subsection{Image analysis}

Autoradiographic films were quantified by digitizing the film images with an Epson Perfection 4990 Photo Scanner and processing them with Image-J software (NIH, Bethesda, MA, USA). The relative optical density (ROD) was measured for VEGF and values were normalized to actin signal. A total of 16 animals were employed ( $n=4$ per experimental condition). The mean value per animal was calculated for statistical analysis.

\subsection{Statistical analysis}

Statistical analysis was performed using SPSS statistical software (version 16.0 for Mac, SPSS, Inc, Chicago, Illinois, USA). Prior to analysis, the data were examined for normal distribution using the Kolmogorov-Smirnov test and for homogeneity of variances using Levene's test. The effects of experimental conditions were evaluated using the one-way ANOVA analysis with the Bonferroni correction for equal variances or Tamhane's T2 correction for unequal variances. Data are described as mean \pm SEM. Significance was declared at $P<0.05$.

\section{Acknowledgments}

This work has been partially supported by grants 491/10 and SAIOTEK from the Government of the Basque Country and UFI 11/32 (UPV-EHU). N. Ortuzar is supported by a predoctoral grant (FPU) from the Spanish Ministry of Education. Confocal microscopy analysis was performed at the "Servicio de Microscopia Analtica y de Alta Resolucion en Biomedicina" (High Resolution Analytical Microscopy Services for Biomedicine) at the University of the Basque Country.

\section{Appendix A.}

\section{Supporting information}

Supplementary data associated with this article can be found in the online version
Adelson, P.D., Jenkins, L.W., Hamilton, R.L., Robichaud, P., Tran, M.P., Kochanek, P.M., 2001. Histopathologic response of the immature rat to diffuse traumatic brain injury. J. Neurotrauma 18, 967-976.

Albayrak, S., Zhao, Q., Siesjö, B.K., Smith, M.L., 1997. Effect of transient focal ischemia on blood-brain barrier permeability in the rat: correlation to cell injury. Acta Neuropathol. 94, 158-163.

Anderson, V., Spencer-Smith, M., Wood, A., 2011. Do children really recover better? Neurobehavioural plasticity after early brain insult. Brain 134, 2197-2221.

Andrews, R.J., 1997. Transhemispheric diaschisis. A review and comment. Stroke 22, 943-949.

Argandoña, E.G., Bengoetxea, H., Lafuente, J.V., 2005. Lack of experience-mediated differences in the immunohistochemical expression of blood-brain barrier markers (EBA and GluT-1) during the postnatal development of the rat visual cortex. Dev. Brain Res. 156, 158-166.

Argandoña, E.G., Bengoetxea, H., Lafuente, J.V., 2009. Physical exercise is required for environmental enrichment to offset the quantitative effects of dark-rearing on the S-100beta astrocytic density in the rat visual cortex. J. Anat. 215, 132-140.

Argandoña, E.G., Lafuente, J.V., 1996. Effects of dark-rearing on the vascularization of the developmental rat visual cortex. Brain Res. 732, 43-51.

Argandoña, E.G., Bengoetxea, H., Lafuente, J.V., 2006. Effects of intracortical administration and neutralisation of vascular endothelial growth factor in the developing rat brain. Int. J. Neuroprot. Neuroregen. 3, 45-52.

Argandoña, E.G., Lafuente, J.V., 2000. Influence of visual experience deprivation on the postnatal development of the microvascular bed in layer IV of the rat visual cortex. Brain Res. 855, 137-142.

Argandoña, E.G., Lafuente, J.V., 2002. The effect of experience on postnatal development of the vascularization of the visual cortex. Rev. Neurol. 340, 983-988.

Argandoña, E.G., Bengoetxea, H., Ortuzar, N., Bulnes, S., RicoBarrio, I., Lafuente, J.V., 2012. Vascular endothelial growth factor: adaptive changes in the neuroglialvascular unit. Curr. Neurovasc. Res. 9, 72-81.

Bastide, M., Ouk, T., Plaisier, F., Pétrault, O., Stolc, S., Bordet, R., 2007. Neurogliovascular unit after cerebral ischemia: is the vascular wall a pharmacological target. Psychoneuroendocrinology 32 (Suppl. 1), S36-S39.

Bengoetxea, H., Argandoña, E.G., Lafuente, J.V., 2008. Effects of visual experience on vascular endothelial growth factor expression during the postnatal development of the rat visual cortex. Cereb. Cortex 18, 1630-1639.

Berardi, N., Pizzorusso, T., Maffei, L., 2000. Critical periods during sensory development. Curr. Opin. Neurobiol. 10, 138-145.

Black, J.E., Isaacs, K.R., Anderson, B.J., Alcantara, A.A., Greenough, W.T., 1990. Learning causes synaptogenesis, whereas motor activity causes angiogenesis, in cerebellar cortex of adult rats. PNAS 87, 5568-5572.

Chu, T., Liu, Y., Wang, Z., Zhu, P., Jiao, W., Wen, J., Gong, S., 2009. Sustained vascular endothelial growth factor blockade by antivascular endothelial growth factor antibodies results in nonunion in the process of fracture healing in rabbits. J. Trauma 66, 1180-1183.

Croll, S.D., Ransohoff, R.M., Cai, N., Zhang, Q., Martin, F.J., Wei, T., Kasselman, L.J., Kintner, J., Murphy, A.J., Yancopoulos, G.D., Wiegand, S.J., 2004. VEGF-mediated inflammation precedes angiogenesis in adult brain. Exp. Neurol. 187, 388-402.

Cunningham, A.S., Salvador, R., Coles, J.P., Chatfield, D.A., Bradley, P.G., Johnston, A.J., Steiner, L.A., Fryer, T.D., Aigbirhio, F.I., Smielewski, P., Williams, G.B., Carpenter, T.A., Gillard, J.H., 
Pickard, D.K., Menon, D.K., 2005. Physiological thresholds for irreversible tissue damage in contusional regions following traumatic brain injury. Brain 128, 1931-1942.

del Zoppo, G.J., 2010. The neurovascular unit, matrix proteases, and innate inflammation. Ann. N.Y. Acad. Sci. 1207, 46-49.

Dobrogowska, D.H., Lossinsky, A.S., Tarnawski, M., Vorbrodt, A.W., 1998. Increased bloodbrain barrier permeability and endothelial abnormalities induced by vascular endothelial growth factor. J. Neurocytol. 27, 163-173.

Duchen, L.W., 1992. General pathology of neurons and neuroglia. In: Adams, J.H., Duchen, L.W. (Eds.), Greenfield's Neuropathology. Oxford University Press, New York, pp. 1-68.

Dvorak, H.F., 2000. VPF/VEGF and the angiogenic response. Semin. Perinatol. 24, 75-78.

Fagiolini, M., Pizzorusso, T., Berardi, N., Domenici, L., Maffei, L., 1994. Functional postnatal development of the rat primary visual cortex and the role of visual experience: dark rearing and monocular deprivation. Vision Res. 34, 709-720.

Ferrara, N., Bunting, S., 1996. Vascular endothelial growth factor, a specific regulator of angiogenesis. Curr. Opin. Nephrol. Hypertens. 5, 35-44.

Ferrara, N., Davis-Smyth, T., 1997. The biology of vascular endothelial growth factor. Endocr. Rev. 18, 4-25.

Ferrara, N., Gerber, H.P., 2001. The role of vascular endothelial growth factor in angiogenesis. Acta Haematol. 106, 148-156.

Ferrara, N., Gerber, H.P., LeCouter, J., 2003. The biology of VEGF and its receptors. Nat. Med. 9, 669-676.

Fineman, I., Giza, C.C., Nahed, B.V., Lee, S.M., Hovda, D.A., 2000 Inhibition of neocortical plasticity during development by a moderate concussive brain injury. J. Neurotrauma 17, 739-749.

Fischer, S., Clauss, M., Wiesnet, M., Renz, D., Schaper, W., Karliczek, G.F., 1999. Hypoxia induces permeability in brain microvessel endothelial cells via VEGF and NO. Am. J. Physiol. 276, 812-820.

Fischer, S., Wobben, M., Marti, H.H., Renz, D., Schaper, W., 2002. Hypoxia-induced hyperpermeability in brain microvessel endothelial cells involves VEGF-mediated changes in the expression of zonula occludens-1. Microvasc. Res. 63, 70-80.

Geretti, E., Shimizu, A., Klagsbrun, M., 2008. Neuropilin structure governs VEGF and semaphorin binding and regulates angiogenesis. Angiogenesis 11, 31-39.

Ghabriel, M.N., Zhu, C., Hermanis, G., Allt, G., 2000. Immunological targeting of the endothelial barrier antigen (EBA) in vivo leads to opening of the blood-brain barrier. Brain Res. 878, 127-135.

Ghabriel, M.N., Zhu, C., Leigh, C., 2002. Electron microscope study of blood-brain barrier opening induced by immunological targeting of the endothelial barrier antigen. Brain Res. 934, 140-151.

Gilbert, C.D., 1998. Adult cortical dynamics. Physiol. Rev. 78, 467-485.

Giza, C.C., Griesbach, G.S., Hovda, D.A., 2005. Experience-dependent behavioral plasticity is disturbed following traumatic injury to the immature brain. Behav. Brain Res. 157, 11-22.

Greenberg, D.A., Jin, K., 2005. From angiogenesis to neuropathology. Nature 438, 954-959.

Greifzu, F., Schmidt, S., Schmidt, K.F., Kreikemeier, K., Witte, O.W., Löwel, S., 2011. Global impairment and therapeutic restoration of visual plasticity mechanisms after a localized cortical stroke. PNAS 108, 15450-15455.

Gurkoff, G.G., Giza, C.C., Hovda, D.A., 2006. Lateral fluid percussion injury in the developing rat causes an acute, mild behavioral dysfunction in the absence of significant cell death. Brain Res. 1077, 24-36.

Harrison, R.V., Harel, N., Panesar, J., Mount, R.J., 2002. Blood capillary distribution correlates with hemodynamic-based functional imaging in cerebral cortex. Cereb. Cortex 12, 225-233.

Hawkins, B.T., Davis, T.P., 2005. The blood-brain barrier/neurovascular unit in health and disease. Pharmacol. Rev. 57, 173-185.

Hensch, T.K., 2005. Critical period mechanisms in developing visual cortex. Curr. Top. Dev. Biol. 69, 215-237.
Hermann, D.M., Zechariah, A., 2009. Implications of vascular endothelial growth factor for postischemic neurovascular remodeling. J. Cereb. Blood Flow Metab. 29, 1620-1643.

Herz, J., Reitmeir, R., Hagen, S.I., Reinboth, B.S., Guo, Z., Zechariah, A., ElAli, A., Doeppner, T.R., Bacigaluppi, M., Pluchino, S., Kilic, U., Kilic, E., Hermann, D.M., 2012. Intracerebroventricularly delivered VEGF promotes contralesional corticorubral plasticity after focal cerebral ischemia via mechanisms involving anti-inflammatory actions. Neurobiol. Dis. 45, 1077-1085.

Hoffmeyer, H.W., Enager, P., Thomsen, K.J., Lauritzen, M.J., 2007. Nonlinear neurovascular coupling in rat sensory cortex by activation of transcallosal fibers. J. Cereb. Blood Flow Metab. $27,575-587$.

Hu, T.T., Van den Bergh, G., Thorrez, L., Heylen, K., Eysel, U.T., Arckens, L., 2011. Recovery from retinal lesions: molecular plasticity mechanisms in visual cortex far beyond the deprived zone. Cereb. Cortex 21, 2883-2892.

Jin, K., Mao, X.O., Batteur, S.P., McEachron, E., Leahy, A., Greenberg, D.A., 2001. Caspase3 and the regulation of hypoxic neuronal death by vascular endothelial growth factor. Neuroscience 108, 351-358.

Jin, K.L., Mao, X.O., Greenberg, D.A., 2000. Vascular endothelial growth factor: direct neuroprotective effect in in vitro ischemia. PNAS 97, 10242-10247.

Kaya, D., Gursoy-Ozdemir, Y., Yemisci, M., Tuncer, N., Aktan, S., Dalkara, T., 2005. VEGF protects brain against focal ischemia without increasing blood-brain permeability when administered intracerebroventricularly. J. Cereb. Blood Flow Metab. 25, 1111-1118.

Khan, M., Im, Y.B., Shunmugavel, A., Gilg, A.G., Dhindsa, R.K., Singh, A.K., Singh, I., 2009. Administration of S-nitrosoglutathione after traumatic brain injury protects the neurovascular unit and reduces secondary injury in a rat model of controlled cortical impact. J. Neuroinflammation 6, 32 .

Kolb, B., Cioe, J., 2003. Recovery from early cortical damage in rats. IX. Differential behavioral and anatomical effects of temporal cortex lesions at different ages of neural maturation. Behav. Brain Res. 144, 67-76.

Krum, J.M., Khaibullina, A., 2003. Inhibition of endogenous VEGF impedes revascularization and astroglial proliferation: roles for VEGF in brain repair. Exp. Neurol. 181, 241-257.

Krum, J.M., Mani, N., Rosenstein, J.M., 2002. Angiogenic and astroglial responses to vascular endothelial growth factor administration in adult rat brain. Neuroscience 110, 589-604.

Lafuente, J.V., Argandoña, E.G., Mitre, B., 2006. VEGFR-2 expression in brain injury: its distribution related to brain-blood barrier markers. J. Neural Transm. 113, 487-496.

Lafuente, J.V., Ortuzar, N., Bengoetxea, H., Bulnes, S., Argandoña, E.G., 2012. Vascular endothelial growth factor and other angioglioneurins: key molecules in brain development and restoration. Int. Rev. Neurobiol. 102, 317-346.

Lecrux, C., Hamel, E., 2011. The neurovascular unit in brain function and disease. Acta Physiol. 203, 47-59 (Oxf).

Lin, B., Ginsberg, M.D., Zhao, W., Alonso, O.F., Belayev, L., Busto, R., 2001. Quantitative analysis of microvascular alterations in traumatic brain injury by endothelial barrier antigen immunohistochemistry. J. Neurotrauma 18, 389-397.

Lodovichi, C., Berardi, N., Pizzorusso, T., Maffei, L., 2000. Effects of neurotrophins on cortical plasticity: same or different? J. Neurosci. 20, 2155-2165.

Lok, J., Gupta, P., Guo, S., Kim, W.J., Whalen, M.J., van Leyen, K., Lo, E.H., 2007. Cell-cell signaling in the neurovascular unit. Neurochem. Res. 32, 2032-2045.

Louissaint, A., Rao, S., Leventhal, C., Goldman, S.A., 2002. Coordinated interaction of neurogenesis and angiogenesis in the adult songbird brain. Neuron 34, 945-960.

Mani, N., Khaibullina, A., Krum, J.M., Rosenstein, J.M., 2005. Astrocyte growth effects of vascular endothelial growth factor 
(VEGF) application to perinatal neocortical explants: receptor mediation and signal transduction pathways. Exp. Neurol. 192, 394-406.

Marti, H.J., Bernaudin, M., Bellail, A., Schoch, H., Euler, M., Petit, E., Risau, W., 2000. Hypoxia-induced vascular endothelial growth factor expression precedes neovascularization after cerebral ischemia. Am. J. Pathol. 156, 965-976.

Maurer, M.H., Tripps, W.K., Feldmann, R.E., Kuschinsky, W., 2003. Expression of vascular endothelial growth factor and its receptors in rat neural stem cells. Neurosci. Lett. 344, 165-168.

Moser, K.V., Humpel, C., 2005. Vascular endothelial growth factor counteracts NMDAinduced cell death of adult cholinergic neurons in rat basal nucleus of Meynert. Brain Res. Bull. 65, 125-131.

Murase, N., Duque, J., Mazzocchio, R., Cohen, L.G., 2004. Influence of interhemispheric interactions on motor function in chronic stroke. Ann. Neurol. 55, 400-409.

Nordal, R.A., Wong, C.S., 2005. Molecular targets in radiationinduced blood-brain barrier disruption. Int. J. Radiat. Oncol. Biol. Phys. 62, 279-287.

Norsted, E., Gomuc, B., Meister, B., 2008. Protein components of the blood-brain barrier (BBB) in the mediobasal hypothalamus. J. Chem. Neuroanat. 36, 107-121.

Oosthuyse, B., Moons, L., Storkebaum, E., Beck, H., Nuyens, D., Brusselmans, K., Van Dorpe, J., Hellings, P., Gorselink, M., Heymans, S., Theilmeier, G., Dewerchin, M., Laudenbach, V., Vermylen, P., Raat, H., Acker, T., Vleminckx, V., Van Den Bosch, L., Cashman, N., Fujisawa, H., Drost, M.R., Sciot, R., Bruyninckx, F., Hicklin, D.J., Ince, C., Gressens, P., Lupu, F., Plate, K.H., Robberecht, W., Herbert, J.M., Collen, D., Carmeliet, P., 2001. Deletion of the hypoxia-response element in the vascular endothelial growth factor promoter causes motor neuron degeneration. Nat. Genet. 28, 131-138.

Ortuzar, N., Argandoña, E.G., Bengoetxea, H., Lafuente, J.V., 2011. Combination of intracortically administered VEGF and environmental enrichment enhances brain protection in developing rats. J. Neural Transm. 118, 135-144.

Ortuzar, N., Argandoña, E.G., Bengoetxea, H., Leis, O., Bulnes, S., Lafuente, J.V., 2010. Effects of VEGF administration or neutralization on the BBB of developing rat brain. Acta Neurochir. Suppl. 106, 55-59.

Palmer, T.D., Willhoite, A.R., Gage, F.H., 2000. Vascular niche for adult hippocampal neurogenesis. J. Comp. Neurol. 425, 479-494.

Payne, B.R., Lomber, S.G., 2002. Plasticity of the visual cortex after injury: what's different about the young brain?. Neuroscientist 8, 174-185.

Pekny, M., Nilsson, M., 2005. Astrocyte activation and reactive gliosis. Glia 50, 427-434.

Plate, K.H., Breier, G., Weich, H.A., Risau, W., 1992. Vascular endothelial growth factor is a potential tumour angiogenesis factor in human gliomas in vivo. Nature 359, 845-848.

Prins, M.L., Lee, S.M., Cheng, C.L., Becker, D.P., Hovda, D.A., 1996. Fluid percussion brain injury in the developing and adult rat: a comparative study of mortality, morphology, intracranial pressure and mean arterial blood pressure. Dev. Brain Res. 95, 272-282.

Reitmeir, R., Kilic, E., Reinboth, B.S., Guo, Z., ElAli, A., Zechariah, A., Kilic, U., Hermann, D.M., 2012. Vascular endothelial growth factor induces contralesional corticobulbar plasticity and functional neurological recovery in the ischemic brain. Acta Neuropathol. 123, 273-284.

Rosenstein, J.M., Mani, N., Khaibullina, A., Krum, J.M., 2003. Neurotrophic effects of vascular endothelial growth factor on organotypic cortical explants and primary cortical neurons. J. Neurosci. 23, 11036-11044.

Ruiz de Almodovar, C., Lambrechts, D., Mazzone, M., Carmeliet, P., 2009. Role and therapeutic potential of VEGF in the nervous system. Physiol. Rev. 89, 607-648.

Schoch, H.J., Fischer, S., Marti, H.H., 2002. Hypoxia-induced vascular endothelial growth factor expression causes vascular leakage in the brain. Brain 125, 2549-2557.

Sirevaag, A.M., Black, J.E., Shafron, D., Greenough, W.T., 1988. Direct evidence that complex experience increases capillary branching and surface area in visual cortex of young rats. Brain Res. 471, 299-304.

Skold, M.K., Risling, M., Holmin, S., 2006. Inhibition of vascular endothelial growth factor receptor 2 activity in experimental brain contusions aggravates injury outcome and leads to early increased neuronal and glial degeneration. Eur. J. Neurosci. 23, 21-34.

Sofroniew, M.V., 2009. Molecular dissection of reactive astrogliosis and glial scar formation. Trends Neurosci. 32, 638-647.

Storkebaum, E., Lambrechts, D., Carmeliet, P., 2004. VEGF: once regarded as a specific angiogenic factor, now implicated in neuroprotection. Bioessays 26, 943-954.

Sun, Y., Jin, K., Xie, L., Childs, J., Mao, X.O., Logvinova, A., Greenberg, D.A., 2003. VEGF-induced neuroprotection, neurogenesis, and angiogenesis after focal cerebral ischemia. J. Clin. Invest. 111, 1843-1851.

Tieman, S.B., Mollers, S., Tieman, D.G., White, J., 2004. The blood supply of the cat's visual cortex and its postnatal development. Brain Res. 998, 100-112.

Tong, W., Igarashi, T., Ferriero, D.M., Noble, L.J., 2002. Traumatic brain injury in the immature mouse brain: characterization of regional vulnerability. Exp. Neurol. 176, 105-116.

Unal-Cevik, I., Kilinc, M., Gursoy-Ozdemir, Y., Gurer, G., Dalkara, T., 2004. Loss of NeuN immunoreactivity after cerebral ischemia does not indicate neuronal cell loss: a cautionary note. Brain Res. 1015, 169-174.

van Bruggen, N., Thibodeaux, H., Palmer, J.T., Lee, W.P., Fu, L., Cairns, B., Tumas, D., Gerlai, R., Williams, S.P., van Lookeren Campagne, M., Ferrara, N., 1999. VEGF antagonism reduces edema formation and tissue damage after ischemia/reperfusion injury in the mouse brain. J. Clin. Invest. 104, 1613-1620.

Vangilder, R.L., Rosen, C.L., Barr, T.L., Huber, J.D., 2011. Targeting the neurovascular unit for treatment of neurological disorders. Pharmacol. Ther. 130, 239-247.

Von Monakow, C., 1914. Die Lokalisation im Großhirn und der Abbau der Funktion durch Kortikale Herde. J.F. Bergmann, Wiesbaden, Germany, pp 26-34.

Wick, A., Wick, W., Waltenberger, J., Weller, M., Dichgans, J., Schulz, J.B., 2002. Neuroprotection by hypoxic preconditioning requires sequential activation of vascular endothelial growth factor receptor and Akt. J. Neurosci. 22, 6401-6407.

Widenfalk, J., Lipson, A., Jubran, M., Hofstetter, C., Ebendal, T., Cao, Y., Olson, L., 2003. Vascular endothelial growth factor improves functional outcome and decreases secondary degeneration in experimental spinal cord contusion injury. Neuroscience 120, 951-960.

Yang, J., Guo, L., Liu, R., Liu, H., 2012. Neuroprotective effects of VEGF administration after focal cerebral ischemia/reperfusion: dose response and time window. Neurochem. Int. 60, 592-596.

Zacchigna, S., Lambrechts, D., Carmeliet, P., 2008. Neurovascular signalling defects in neurodegeneration. Nat. Rev. Neurosci. 9, 169-181. 